\title{
Attachment Styles: Fear of Compassion and Callous-Unemotional Traits among Juvenile Delinquents
}

\section{Khairuzaman Maziatul Akmal ${ }^{1 *}$ and Andrew L. S. Foong ${ }^{2}$}

${ }^{1}$ Department of Human Development and Family Studies, University Putra Malaysia, Malaysia

${ }^{2}$ College of Health \& Medicine, University of Tasmania, Rozelle Campus, Lilyfield, NSW 2040, Australia

*Corresponding author: Khairuzaman Maziatul Akmal, Department of Human Development and Family Studies, University Putra Malaysia, Malaysia, Tel: +60134890522; E-mail: maziatulakmal.kz@gmail.com

Received date: Feb 14, 2018, Accepted date: Feb 28, 2018, Published date: Mar 10, 2018

Copyright: 2018 @ Maziatul Akmal K, et al. This is an open-access article distributed under the terms of the Creative Commons Attribution License, which permits unrestricted use, distribution, and reproduction in any medium, provided the original author and source are credited.

\begin{abstract}
Literature on adolescent delinquency indicated strong family bonds acted as protective factors against delinquent behaviors, hence brings significance to study attachment styles. The purpose of the present study is to determine the relationship between Fear of compassion and then, Callous-unemotional traits in relation to attachment styles. The study further examined the relationship between Fear of compassion and Callous-unemotional traits. A purposive sample of 177 adolescents in detention centers were assessed using a Relationship Questionnaire with Fear of Compassion Scale and Inventory of Callous-unemotional Traits - Youth. Findings of the study indicated Fear of compassion is not significant in relation to attachment styles. However, Callous-unemotional traits were significantly related to attachment styles. Additionally, Fear of Compassion suggested predictive value to Callousunemotional traits. The study provides a contextual perspective on the importance of attachments styles in the wider context of familial relationships for adolescents.
\end{abstract}

Keywords: Attachment styles; Fear of compassion; Callousunemotional traits; Juveniles; Delinquency

\section{Introduction}

Recent data suggest a global increment of juveniles in conflicts with the law [1]. It is consistent with the scenario in Malaysia [2], with a recorded 1,632 criminal cases in 2014 compared with 1,042 cases in 2012 (an increase of 57\%), in all sectors of criminal acts committed by juveniles [3]. Studies were conducted within the country to understand the causes of misdemeanor by juveniles. One of the trends found in juvenile delinquents is mostly poor relationships with their parents [4,5], supported by a meta-analysis on the attachment of parent, peer and child, with delinquency [6]. It appears that situations of deficits in receiving affection and companionship by caregivers that occur concurrently in juvenile delinquents are in need of further studies [7].

Recent studies on youths with antisocial behaviours suggest callousness and unemotional traits to be contributory factors for difficulties in forming interpersonal relationships following release from institutions [8-11]. Furthermore, it has been reported that a subtype of juveniles with high callousness do not respond well with traditional rehabilitation strategies such as disciplinary actions but have higher aggression tendencies $[9,12,13]$. What is lacking, are studies on juvenile delinquents and attachment styles along with Callous-Unemotional Traits and Fear of Compassion which may be important components that fuel the acts of delinquency [9]. With these aspects in mind, we shall outline them in the following sections to help put them in contextual perspective.

\section{Attachment styles}

One of the constructs that have been associated with juveniles' conduct behaviors is that of attachment styles $[6,7,14]$. Attachment in humans can be described as the connectedness in relationships with others [15]; seen as important components that influence interpersonal relationships [16-19]. As a consequence, early representations of childhood relationships with parents leads to the generalization for future "attachment-related thoughts, feelings, and behaviors" [16]. In this study, the focus would be on four attachment styles that are heavily influenced by Bowlby's [20-22] and Ainsworth's [17] theory of attachment which are secure attachment style and three insecure attachments namely anxious-preoccupied, dismissive avoidant and fearful avoidant [23-25].

Secure attachment styles in toddlers occur when the attachment figure provides a secure and safe environment that develops into a stable trust amongst parent-infant relationships, that is then manifested in future social interactions [21-23]. In contrast, individuals with insecure attachment styles have profound difficulties in forming trusting social relationships. For example, anxiouspreoccupied or ambivalent infants explore without confidence, exhibiting mixed emotions of resisting and seeking emotional contact, meanwhile avoidant infants actively avoid emotional contact with their caregivers [26].

The regulation of emotions is heavily influenced by childhood developmental experiences [27]. The presence of attachment security helps facilitate understanding of negative emotions and lesser avoidance of the topic when caregivers are capable of validating their emotions [28]. Insecure attachments increases perceived risk of rejection and social withdrawal from their surroundings. That, then, induces feelings of uselessness that may result to further psychopathological problems $[29,30]$. The consequence of difficulties in regulating emotions due to insecure attachment styles may channel children's view of the environment which makes them less capable of responding to traumatic experiences effectively [31]. Such insecure attachment style has been linked to susceptibility for development of 
Fear of Compassion, as reflexes are built in to flee from uncomfortable feelings [32]. This can be further understood by examining evidence that supports the relationship of attachment styles in relation to Fear of Compassion [33].

\section{Fear of compassion in relation to attachment styles}

Consistent with the concept outlined in the previous section, the literature supports the impact of attachment security on compassion leading to amelioration of social interactions [34,35]. Compassion from others could trigger a desire for affection, but it could create a sense of grief that is overwhelming for insecurely attached individuals resulting in blocking and denying the emotion [36]. Individuals with insecure attachment styles that are related to the feelings of neglect and abandonment could respond negatively or be avoidant when compassion is present [37]. This understanding leads to the possibility of the development of fear towards the positive emotions due to the insecure attachment system as avoidant attachment patterns are found in individuals with difficulties in expressing themselves similar with those with Fear of compassion for others [38].

As the need for affection builds, but remain unfulfilled, an avoidance of the compassionate behavior and emotions may occur, as a mode to defend themselves from the emotional pain that may emerge [36]. The emergence of fear may be explained using the Behavioral Approach System and the Behavioral Inhibition System (BAS/BIS) theory [39]. In effect, the two systems create a scheme for acceptance of positive emotions that are currently injured that leads to avoidance of the emotion [40]. However, understanding of the fear and resistance to affiliative emotions and compassion is limited on the consequence of the attachment theory [37] and clinical studies [41-43].

\section{Callous-unemotional traits in relation to attachment styles}

Much of the literature suggested that children with high Callousunemotional traits have tendencies for psychopathy due to repercussions from challenging childhood developments $[9,44,45]$. A recent study on the presence of Callous-unemotional traits on different attachment styles indicated insecure attachment, and more specifically the disorganized attachment style is associated with higher levels of Callous-unemotional traits [45]. It is supported by a study demonstrating that children who have high Callous-unemotional traits and who display avoidance of eye-contact behaviors with their caregiver have maternal reports of negative feelings towards the child [46]. Nonetheless, both of the studies reflect upon the construct of insecure attachment development from infancy and childhood, suggesting the major influence of caregivers in the development of attachment styles, which may result in difficulties with emotional regulation [47]. However, there is a lack of studies on children with high Callous-unemotional traits that explain the emotional responsiveness due to the influence of the attachment relationships [48]. Hence, the present study will seek to gain insights on the possible relationships that may lead to the development of the traits.

From childhood experiences with caregivers, individuals' protect their emotional well-being unconsciously as a defense that allows them to feel safer in facing uncomfortable situations $[49,50]$. This creates the possibility for suppression of emotions to induce callousness and unemotional traits [51]. As portrayed in a study by Pasalich, et al. [45], insecure attachment styles, especially that of avoidant attachment style, may have associations with the development of the traits. This is because there is a possibility for insecure attachment styles to be a risk relational factor with projection of disregard towards others and hostile attribution that is common in those that acquire the Callousunemotional trait [52]. To date, there does not appear to be any study that examines the degree of Callous-unemotional traits in relation to attachment styles despite growing interest on its impacts.

\section{Fear of compassion and callous-unemotional traits}

With the background outlined earlier one question is the possibility of a relationship between Fear of compassion and Callousunemotional traits whereby escaping from compassion by avoidance, may result in behavioural adaptation that may lead to detachment from the emotion altogether [39]. It is based on the understanding that Fear of compassion is defined as avoidance of empathetic and affective emotions [53], while Callous-unemotional traits refer to deficits or lack of affective emotions [9]. The study that supports the similarity effect of the Callous-unemotional traits in relation to Fear of compassion mentioned the limited emotional depth, low regards of others, and lack of guilt that is due to the mechanism of avoidance of the compassionate feeling [48]. With that in mind, this study will investigate the link that Callous-unemotional traits may have been developed from the presence of high level of Fear of compassion and hopefully enhance understanding of attachment styles.

\section{Aim of Study}

The purpose of the present study is three-fold. Firstly, it aims to determine the relationship between Fears of compassion in relation to attachment styles. Secondly, the study examines the relationship between Callous-unemotional traits in relation to attachment styles. Thirdly, the study seeks to determine if Fear of compassion and Callous-unemotional traits are further related. That may serve to give us a bigger picture of how attachments styles are important in the wider context of familial relationships and conceptualising understanding of attachment styles in adolescents.

\section{Methods and Procedure}

\section{Research design}

A total of 193 participants were recruited using purposive sampling from two detention centers in the state of Malacca. The inclusion criteria are that participants must be adolescents within the delinquent school system within the age range of 13-18 years. Both genders were obtained by recruiting participants from both of the schools to avoid gender bias. The participants were administered with three selfreported questionnaires for the study. However, due to unforeseen completion of the questionnaires by some participants, only 177 participants' responses were included in this study.

\section{Materials}

During the course of the study, a study info sheet, informed consent form, a demographic questionnaire and three self-reported questionnaires were administered. The questionnaires are as listed below:

1. Demographic questionnaire, consisted of questions to categories the participants in terms of gender, age, race, family status and order among siblings. These questions were required to enable identification of patterns within the population and the variables studied. 
2. Relationship questionnaire [25] is a four-item questionnaire that categorises an individual into the four forms of attachment styles which are secure attachment style and three insecure attachments which are anxious-preoccupied, dismissive avoidant and fearful avoidant. Validation of the questionnaires are found in the constructs on attachment interviews of secure and fearful ratings $r(75)=-0.55$, $\mathrm{p}<0.001$; and preoccupied and dismissing ratings, $\mathrm{r}(75)=-0.50$, $\mathrm{p}<0.001$. Correlation of self-report and friends report attachment rating further validated the questionnaire [25].

3. Fear of compassion scale [36] scores the sum of three constructs, namely, fear of positive emotions, fear of compassion towards self and fear of compassion towards others. The scale has internal validities of 0.92 for fear of compassion for self; 0.85 for fear of compassion from others and 0.84 for fear of compassion for others. Items were presented on a Likert scale of 0 as "Don't agree at all" to 4 as "Completely agree". The subscales of Compassion for self (positive emotions) has 15 items, Compassion from others has 13 items and lastly, Compassion towards Others has 10 items [36].

4. Inventory of Callous-unemotional traits - Youth [54] is a scale that assesses the three themes within the Callous-unemotional trait, namely: uncaring, unemotional and callousness. It has 24 items, rated on a Likert scale from 0 as "Not at all true" to 3 "Definitely true". Confirmatory analysis results show consistencies of three independent factors relating to a higher-order Callous-unemotional dimension. In that study, there was correlation of Empathy and Positive Affect scales Emotional-Quotient Inventory or EQI $(r=-0.51$ and $r=-0.46, p<0.001$ ) and Callous-Unemotional construct of the Antisocial Process Screening Device or APSD by $(r=0.45$, ICU total; $r=0.32$, Uncaring; $\mathrm{r}=0.36$ Callous; all $\mathrm{p}<0.001$ ), thus, determining the construct validity of the scale.

\section{Translation of the questionnaires/scales}

The self-reported questionnaires were available only in English. Due to the fluency in Bahasa Malaysia of the population, translation of the English version questionnaire to Bahasa Malaysia was executed using the back-translation method [55]. A pilot study was carried out on adolescents that are fluent in Bahasa Malaysia. Inputs in regards to the difficulty of the questionnaires were collected to further increase comprehension of the questionnaire. Throughout the study, only the translated Bahasa Malaysia version was used for the study.

\section{Procedure}

Following approval from the International Medical University Ethics Committee requests letters to conduct the study and the study proposal were sent via online application to the relevant government authority, 'JKM.GOV.MY'. The questionnaires were translated piloted and indicated in the previous section. With the feedback, test revision was done and then the questionnaires were back-translated to English again, it showed no change of meaning in all three questionnaires. Once the approval and informed consent had been granted by the Welfare Department of Malaysia, appointments were scheduled to conduct the study with participants from two delinquent schools. Informed consents of the youths were obtained following explanations in Bahasa Malaysia regarding the confidentiality and their rights as participants such as withdrawal rights if requested. The questionnaires were collected after their completion.
Data analyses were undertaken with one-way MANOVA with one categorical predictor that is the four different attachment styles against two continuous dependent variables that are the Fear of compassion and Callous-unemotional traits. Between the Fear of compassion and Callous-unemotional traits, a multiple regression was conducted to examine the relationship between the different types of Fear of compassion and Callous-unemotional traits. The data were also analysed using multiple regression between Fear of compassion and Callous-unemotional traits. A reliability test was also carried out with the provided data.

\section{Results}

The mean age of the participants was 16 years with a mode of 17 consisted of 51 participants ( $\mathrm{SD}=1.617, \mathrm{~N}=177$ ). The mean age for the male adolescents was 14 years with a mode of 13 years $(\mathrm{SD}=1.609$, $\mathrm{N}=43$ ) and for the females was 16 years; the mode was 17 years with 42 of the participants ( $\mathrm{SD}=1.196, \mathrm{~N}=134$ ).

Preliminary analysis shows, almost all of the sample were Malay (92.2\%) with the remainder from Indian (5.0\%), Chinese $(1.7 \%)$ and Sabahan and Sarawakian (1.1\%). Most of the adolescents in the detention centers had both of their biological parents married (40.8\%), while the second highest percentage of $24.6 \%$ were divorced, followed by widowed parents $(16.2 \%)$, orphaned or unrecorded parents $(15.1 \%)$ and lastly $3.4 \%$ had unmarried parents. The sample size collected is adequate given the suggested sample of 148, to achieve a confidence level of $95 \%$, with a margin error of $5.0 \%$.

Table 1 shows The Multivariate test of Attachment styles factor ( $\mathrm{F}$ $(12,439)=1.793 ; \mathrm{p}=0.047)$ and the Gender factor $(\mathrm{F}(4,166)=7.312$; $\mathrm{p}=0.001)$ are statistically significant. The univariate tests show that only attachment styles and Callous-unemotional traits $(F(3,169)=2.912 ; p=0.036)$ and gender towards fear of compassion towards others $(\mathrm{F}(1)=23.073 ; \mathrm{p}=0.001$.) towards other show statistically significant differences. Therefore, based on this analysis, post hoc has been done to see the differences and relationship of the significant results.

Pairwise comparison was observed for gender differences in fear of compassion towards others, while post hoc was conducted for attachment styles and Callous-unemotional traits as there are more than two variables measured as shown in Table 2.

Callous-unemotional traits present statistically significant mean differences between Dismissive-Avoidant Attachment in comparison to Fearful-Avoidant Attachment $(\mathrm{p}=0.40)$ with a bigger mean difference of 3.11 and Dismissive-Avoidant Attachment compared to Anxious-Preoccupied Attachment $(p=0.033)$ with a bigger mean difference of 3.62.

As for the analysis of gender and Fear of Compassion towards others was also analyzed presenting results of Females has higher mean in fear of compassion towards others in comparison to males with a mean difference of $5.370(\mathrm{p}=0.001)$.

Other than that, multiple regression analysis was used to test if the different types of Fear of compassions significantly predicted Callousunemotional traits. Data analysis for multiple regressions was done using the backward method because it allows the emergence of the best predictor while showing the differences of the prediction value of each one through elimination [56]. 
Citation: Maziatul Akmal K, Foong ALS (2018) Attachment Styles: Fear of Compassion and Callous-Unemotional Traits among Juvenile

\begin{tabular}{|c|c|c|c|c|c|c|}
\hline Source & Dependent Variable & df & $\mathbf{F}$ & Sig. & $\begin{array}{l}\text { Partial } \\
\text { Squared }\end{array}$ & Observed Power \\
\hline \multirow[t]{4}{*}{ AttachStyle } & Callous Unemotional Traits & 3 & 2.912 & 0.036 & 0.049 & 0.686 \\
\hline & Fear of Compassion towards others & 3 & 0.869 & 0.458 & 0.015 & 0.237 \\
\hline & Fear of Compassion from others & 3 & 1.735 & 0.162 & 0.030 & 0.447 \\
\hline & Fear of Positive Emotions & 3 & 0.330 & 0.804 & 0.006 & 0.113 \\
\hline \multirow[t]{4}{*}{ Gender } & Callous Unemotional Traits & 1 & 1.337 & 0.249 & 0.008 & 0.210 \\
\hline & Fear of Compassion towards others & 1 & 23.073 & 0.000 & 0.120 & 0.998 \\
\hline & Fear of Compassion from others & 1 & 1.037 & 0.310 & 0.006 & 0.173 \\
\hline & Fear of Positive Emotions & 1 & 0.944 & 0.333 & 0.006 & 0.162 \\
\hline \multirow[t]{4}{*}{ AttachStyle Gender } & Callous Unemotional Traits & 3 & 0.901 & 0.442 & 0.016 & 0.245 \\
\hline & Fear of Compassion towards others & 3 & 0.310 & 0.818 & 0.005 & 0.109 \\
\hline & Fear of Compassion from others & 3 & 0.440 & 0.725 & 0.008 & 0.137 \\
\hline & Fear of Positive Emotions & 3 & 2.125 & 0.099 & 0.036 & 0.535 \\
\hline
\end{tabular}

Table 1: Univariate Tests between attachment styles and gender.

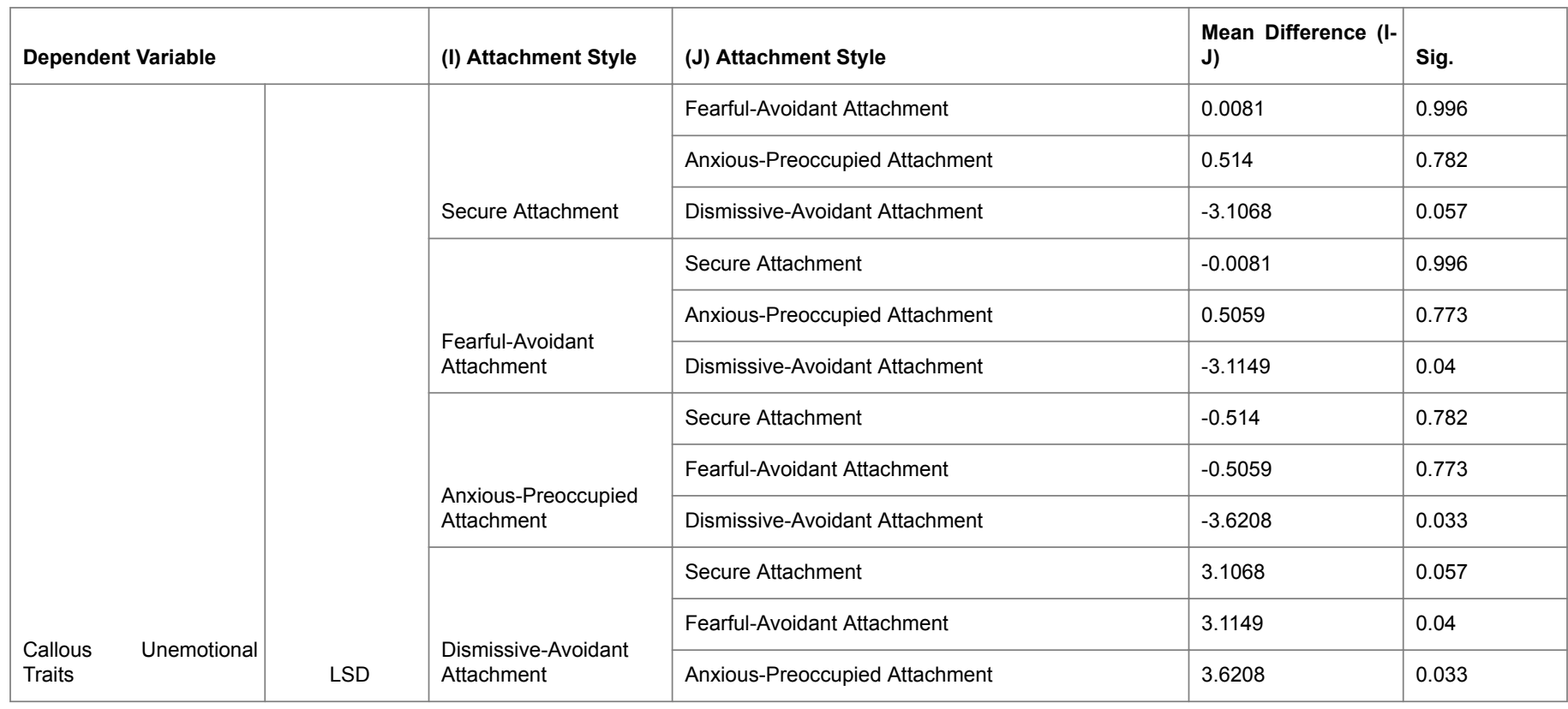

Table 2: Post Hoc Test on Attachment styles and Callous-unemotional traits.

After meeting the assumptions of multiple regression analysis, the results of the regression indicated the two predictors explained $4.3 \%$ of the variance $(\mathrm{R} 2=0.043, \mathrm{~F}(2,174)=3.882, \mathrm{p}=0.022, \mathrm{p}<0.05)$. As shown in Table 3, It was found that Fear of compassion from others significantly predicted Callous-unemotional traits $(\beta=-0.200, \mathrm{p}<0.001)$, as did fear of compassion positive emotions $(\beta=0.176, p<0.05)$. The results obtained shows that for fear of compassion from others $(\mathrm{F}(1,173)=-2.098 ; \quad \mathrm{p}=0.037)$ and fear of positive emotions $(\mathrm{F}(1,173)=2.679 ; \mathrm{p}=0.008)$ has statistically significant prediction values towards Callous-unemotional traits. This results shows that a change of
-0.185 standard values of fear of compassion from others or 0.237 standard values of fear of compassion positive emotions results in a change one standard deviation value of Callous-unemotional traits. However, by looking at the $\mathrm{R}$ square value of fear of compassion from others and fear of compassion of positive emotions are only $4.3 \%$ that is a low prediction value. Nonetheless, the results show a likely possibility of a relationship between certain types of Fear of compassion with Callous-unemotional traits.

Additional analysis of reliability is done to ensure the reliability of the scales to be used in this population as shown in Table 4. The 
Cronbach Alpha in all the scales are above 0.6 which has moderate reliability scores.

\begin{tabular}{|l|l|l|l|l|l|l|l|}
\hline \multirow{2}{*}{ Model } & \multirow{2}{*}{ Unstandardized Coefficients } & \multicolumn{2}{|l|}{$\begin{array}{l}\text { Standardized } \\
\text { Coefficients }\end{array}$} & T & \multicolumn{2}{l|}{ Sig. } & \multicolumn{2}{|l|}{ Collinearity Statistics } \\
\cline { 2 - 8 } & B & Std. Error & Beta & & & Tolerance & VIF \\
\hline Fear of Compassion from others & -0.2 & 0.096 & -0.185 & -2.098 & 0.037 & 0.705 & 1.418 \\
\hline Fear of Positive Emotions & 0.176 & 0.066 & 0.237 & 2.679 & 0.008 & 0.705 & 1.418 \\
\hline
\end{tabular}

Table 3: Coefficient table of multiple regression of different types of fear of compassion against callous-unemotional traits.

\begin{tabular}{|l|l|l|}
\hline Questionnaire (Items) & Cronbach Alpha & No of items \\
\hline Fear of Compassion Towards Others & 0.667 & 10 \\
\hline Fear of Compassion From Other & 0.648 & 13 \\
\hline Fear of Compassion Positive Emotions & 0.819 & 15 \\
\hline Inventory of Callous-Unemotional Traits & 0.617 & 24 \\
\hline
\end{tabular}

Table 4: Cronbach Alpha for reliability test of items.

\section{Discussion}

In contrast to the literature, the results did not support the first hypothesis, whereby there are no significant mean differences between different attachment styles and fear of compassion. This finding may be explained due to the different aspects such as individual differences including age, the social desirability factor and gender, cultural understanding of Fear of compassion and limitation of convenience sampling. First of all, at this adolescent stage, there are relentless peer discriminations as mentioned in previous research by Huynh and Fuligni [57]. The presence of possible peer discrimination if the participants are indifferent to one another may have impacted the results. Another possible explanation for this occurrence is the socialdesirability factor. According to Ray, et al. [58], adolescents who have conduct problems find it easier to answer positive extremities and harder to answer lower social acceptable questions. Therefore, the aspect that Fear of compassion scales questions is mostly constructed to be of lower socially acceptable situations might have caused difficulty for the participants to respond. Other than that, the number of female participants in this study is higher by three-fold which may have highly affected the results as females have tendencies to have a high Fear of compassion [36,41]. In terms of cultural differences, that language sensitivity may have occurred as "fear" is considered to be self-defeating character, thus admitting to having fear may seem disadvantageous in order to regain community acceptance that is vital in the Asian culture [59,60]. Lastly, although purposive and convenience sampling is needed in the study due to the specific population, it may be a possible source of error that had affected the results as it caused an under-representation or over-representation of the population.

For the mean differences between attachment styles in relation to Callous-unemotional traits, the main difference was a higher dismissive-avoidant mean in comparison to fearful avoidant supporting the second hypothesis. Individuals with dismissiveavoidant attachment style have tendencies to generally disregard emotions. This may have resulted in emotional disconnection behaviours, more similar to Callous-unemotional traits than fearful avoidant $[61,62]$. On the other hand, fearful-avoidant attachment individuals may have a concern of the emotions that emerge, which shows the presence of emotional acknowledgement and response. However, the fear evoked due to learned rejection of their emotional needs may cause interpersonal connection distances [63] Interestingly, the study has different outcomes compared with a recent western study on children where avoidant attachments are not associated with Callous-unemotional traits [45]. It is possible that Asian cultural values with lesser positive social interactions between caregivers and child may lead to avoidant attachment strategies by the child to be more positively adaptive [64]. Hence, the development of avoidant attachment is beneficial for them than secure attachments [64,65].

The findings also suggest that dismissive-avoidant attachment is more dominant compared to anxious-preoccupied attachment individuals. As mentioned above, there may be prominent detachment features in dismissive-avoidant individuals in comparison to anxiouspreoccupied who yearn for belongingness and emotional connection [61]. Anxious-preoccupied attachment individuals desire attention. In doing so, there is a higher regard for others' thoughts and emotions compared to dismissive-avoidant attachment individuals $[45,66]$. However, the presence of disappointment or attachment anxiety evoked by unrealised affection or affirmation from others may impact on anxious-preoccupied individuals increasing the probability for manifestation of Callous-unemotional traits.

On the whole, it is suggested that people with dismissive-avoidant attachment may be less likely to be affected by forms of affection or needs for affection. Of importance, it may seem that the dismissiveavoidant attachment results indicate a plausible similarity with the Callous-unemotional traits characteristic. This may be explained by the fact that individuals with dismissive-avoidant attachment styles exhibit callousness, unemotional and uncaring features.

Lastly, the third hypothesis is supported by the findings as there are different types of Fear of compassion that predicts Callousunemotional traits. It is interesting to note that in all the three types of 
Fear of compassion, two out of three of the types of Fear of compassion shows significant prediction possibility towards Callous-unemotional traits. They are fear of compassion from others and fear of compassion positive emotions. This finding suggests that a decrease of fear of compassion from others increases Callous-unemotional traits. It may be explained by the mechanism of eradicating fear from memory [67]. For instance, when individuals disregard the fear of people's perception towards them, it promotes de-empathizing behaviour, hence dissociating one from being emotionally involved [36,41,67]. In addition to that, elimination of fear of compassion from others may have been reinforced in the population as it indicates social dominance that is regarded as "rewarding" [68]. One anticipated finding was that an increase of fear of compassion positive emotions predicts an increase of Callous-unemotional traits. This result shows promising similarities with contemporary literature as individuals in this population has tendencies of higher depression traits and low selfesteem that is also high in individuals with fear of compassion positive emotions $[36,41,69]$. With that, it may lead to dissociation of needs for positive responses and thoughts [68,70]. Another reason to explain this result may be due to the learnt behaviour to avoid from experiencing positive emotions. Based on cognitive appraisal theory and Behavioural Inhibition Scheme /Behavioural Activation Scheme theory, undesirable meaning towards positive emotions may have induced fear of positive emotions $[39,49]$. Theoretically, fear of positive emotions could have been conditioned to eliminate the need for positive affiliations in, and avoid dependency for it [71].

\section{Reliability of the scales}

A moderate to high Cronbach alpha was obtained from the items in all the questionnaires shows the promising reliability of the scales in this population in Malaysia. It suggests that the items are good but probably could be improved [72]. Reliability of all the Fear of Compassion scales [36] showed that it is reliable to be used in juvenile populations in Malaysia. This is similar to findings with noninstitutionalised populations in the western population $[36,69,73]$. Other than that, the Inventory of Callous-Unemotional Traits [74,75] that is popularly used in conduct problem juveniles is also seen as reliable to be used within this population in Malaysia. This is supported by similar findings of Ray et al. [58], Roose et al. [76] and Kimonis et al. [77].

\section{Limitations and Suggestions}

Due to the pioneer usage of the scales in this population, the findings lack resources to support the findings. It is also important to note the need for an officially translated questionnaire as the translated questionnaire in this study is considered as a piloted questionnaire. This may strengthen the reliability and validity of the questionnaires to be used in this population. On top of that, being one of the first Asian populations for the study on Callous-unemotional traits, a need for cross-cultural research is needed, as there are possibilities that individualistic culture [78,79] countries may have different understanding and emphasis in acknowledging the Fear of compassion and Callous-unemotional traits.

Besides that, using quantitative measures limited the study from a deeper understanding of the variables based on the thoughts and behaviors of the students that may be more expressive than what can be seen on pen and paper. Therefore, it is suggested that use of qualitative measures or even mixed methods may provide richer data of depth for the current situation and emotions the adolescents go through. In order to improve the external validity, there is a need to increase on sample spread of the population for future studies, as increasing sample size would increase the chance of finding associations of Fear of compassion and Callous-unemotional traits [80-83]. In addition to that, a replication of incarcerated adolescents may provide new insights or findings in comparison to detention centers as the culture, exposure to the environment and level of delinquency differ.

\section{Research Implications}

This study has served to provide further insights for improvement of the juvenile system as well as alluding to positive approaches for Callous-unemotional traits individuals [84-87]. It is crucial for improvements in the rehabilitation programs and may well open up opportunities for programme enhancements for the betterment of the adolescents. Besides that, the findings show a promising, albeit preliminary, relationship between attachment styles, Fear of compassion and Callous-unemotional traits that may trigger future studies that may help in determining better options of therapeutic approaches. The findings have provided insights into the confounding factors to be considered such as individual differences and culture when implementing emotional regulation assessments.

\section{Conclusion}

Overall, attachment style is a significant variable to consider in addressing the challenges of juveniles in relation to Callousunemotional traits. Although, the present study did not find significant association of attachment styles and Fear of compassion, possibly be due to cultural differences or individual differences, Fear of compassion shows positive relationship with Callous-unemotional traits, hence providing further insights for a more comprehensive conceptualisation of the subject.

\section{References}

1. Johnson JJ, Johnson AO, Johnson A, Senesie T (2016) Juvenile Delinquency in Western, Sierra Leone: Causes and Characteristics of Offenders. Indian J Appl Res 6.

2. Jabatan Kebajikan Masyarakat (JKM) (2016) Laporan Statistik Jabatan Kebajikan Masyarakat 2015 (p. 25). Malaysia: Jabatan Kebajikan Masyarakat (JKM).

3. Muzammil B (2014) Young And Certainly Getting Dangerous: The Rise Of Juvenile Criminals.

4. Jia Choon L, Hasbullah M, Ahmad S, Shin Ling W (2013) Parental Attachment, Peer Attachment, and Delinquency among Adolescents in Selangor, Malaysia. Asian Social Science 9.

5. Hamid S, Nawi A (2013) Family Characteristics Associate with Risk Taking Behaviour among Urban and Rural Adolescents in Two Districts in Selangor: A Comparative Study. Procedia - Soc Beh Sci 91: 581-587.

6. Hoeve M, Stams G, van der Put C, Dubas J, van der Laan P, et al. (2012) A Meta-analysis of Attachment to Parents and Delinquency. J Abnorm Child Psychol 40: 771-785.

7. Abd Rahim AR, Sufean H, Che Hashim H (2006) Krisis \& Konflik Institusi Keluarga. Kuala Lumpur. Utusan Publications.

8. Lau KSL, Marsee MA (2013) Exploring narcissism, psychopathy, and Machiavellianism in youth: Examination of associations with antisocial behaviour and aggression. J Child Fam Stud 22: 355-367.

9. Frick PJ, White SF (2008) Research review: The importance of callousunemotional traits for developmental models of aggressive and antisocial behaviour. J Child Psychol Psychiatry 49: 359-375. 
10. Lawing K, Frick PJ, Cruise KR (2010) Differences in offending patterns between adolescent sex offenders high or low in callous-unemotional traits. Psychol Assess 22: 298-305.

11. Kassim AW (2006) Juveniles on remand: Trends and practices in Malaysia. Resource material series/United Nations Asia and Far East Institute for the Prevention of Crime and the Treatment of Offenders 68: 196-208.

12. Frick P, Ray J (2014) Evaluating Callous-Unemotional Traits as a Personality Construct. J Pers 83: 710-722.

13. Viding E, Fontaine NM, McCrory EJ (2012) Antisocial behaviour in children with and without Callous-unemotional traits. J R Soc Med 105: 195-200.

14. Omar N, Mustaffa CS, Nordin MZF (2007) A comparison of family communication and institutional communication of boarding school students and juveniles in Malaysia. Intercult Commun Stud 16: 72.

15. Chapple CL (2003) Examining intergenerational violence: Violent role modeling or weak parental controls? Violence Vict 18: 143-162.

16. Crowell J, Waters E (2005) Attachment representations, secure-base behaviour, and the evolution of adult relationships. Attachment from infancy to adulthood: The major longitudinal studies 223-244.

17. Ainsworth MDS (1991) Attachments and other affectional bonds across the life cycle. Attachment across the life cycle 33-51.

18. Ainsworth MDS (1979) Attachment as related to mother-infant interaction. Advances in the study of behaviour 9: 1-51.

19. Ainsworth MDS, Blehar MC, Waters E, Wall S (1978) Patterns of attachment: A psychological study of the strange situation. Earlbaum, Hillsdale, NJ.

20. Bowlby J (1980) Loss: Sadness and depression. Attachment and loss, (Volume 3). Hogarth Press, London.

21. Bowlby J (1973) Separation, anxiety and anger: Attachment and loss, (Volume 2). Hogarth Press, London.

22. Bowlby J (1969) Attachment: Attachment and loss, (Volume 1). Hogarth Press, London.

23. Bretherton I (2005) In Pursuit of the Internal Working Model Construct and Its Relevance to Attachment Relationships. Attachment from infancy to adulthood: The major longitudinal studies 13-47.

24. Cassidy J (2002) Handbook of attachment: Theory, research, and clinical applications. Rough Guides.

25. Bartholomew K, Horowitz LM (1991) Attachment styles among young adults: a test of a four-category model. J Pers Soc Psychol 61: 226.

26. Bartholomew K, Kwong MJ, Hart SD (2001) Attachment, in Handbook of personality disorders: Theory, research and treatment 196-230. Guilford, New York.

27. Marusak HA, Martin KR, Etkin A, Thomason ME (2015) Childhood trauma exposure disrupts the automatic regulation of emotional processing. Neuropsychopharmacology 40: 1250-1258.

28. Waters SF, Virmani EA, Thompson RA, Meyer S, Raikes HA, et al. (2010) Emotion Regulation and Attachment: Unpacking Two Constructs and Their Association. J Psychopathol Behav Assess 32: 37-47.

29. Kim S, Sharp C, Carbone C (2014) Personality Disorders: Theory, Research, and Treatment 5: 125.

30. Finzi R, Ram A, Har-Even D, Shnit D, Weizman A (2001) Attachment styles andaggression in physically abused and neglected children. J Youth Adolescence 30: 769-786.

31. Brumariu LE, Kerns KA (2013) Pathways to anxiety: Contributions of attachment history, temperament, peer competence, and ability to manage intense emotions. Child Psychiatry Hum Dev 44: 504-515.

32. Kihlstrom JF (2013) The person-situation interaction. The Oxford handbook of social cognition 786-805.

33. Gilbert P, Irons C (2005) Focused therapies and compassionate mind training for shame and self-attacking. Compassion: Conceptualisations, research and use in psychotherapy 263-325.

34. Mikulincer M, Shaver PR (2012) An attachment perspective on psychopathology. World Psychiatry 11: 11-15.
35. Mikulincer M, Shaver PR (2005) Attachment security, compassion, and altruism. Curr Dir Psychol Sci 14: 34-38.

36. Gilbert P, McEwan K, Matos M, Rivis A (2011) Fears of compassion: Development of three self-report measures. Psychology And Psychotherapy: Theory, Research And Practice. Psychol Psychother 84: 239-255.

37. Mikulincer M, Shaver PR (2007) Attachment in adulthood: Structure, dynamics, and change. Guilford, New York.

38. Grossman K, Grossman KE, Schwann A (1986) Capturing the wider view of attachment. A re-analysis of Ainsworth's Strange Situation. In: Elzard C, Read P (eds.) Measuring emotions in infants and children, 124-171. Cambridge University Press, New York.

39. Gray JA (1994) Framework for a taxonomy of psychiatric disorder. In: van Goozen SHM, de Poll V, Nanne E (eds.) Emotions: Essays on emotion theory 29-59. Lawrence Erlbaum Associates, Inc, Mahwah, NJ.

40. Öhman A, Mineka S (2001) Fears, phobias, and preparedness: toward an evolved module of fear and fear learning. Psychol Rev 108: 483.

41. Gilbert P, McEwan K, Gibbons L, Chotai S, Duarte J, et al. (2012) Fears of compassion and happiness in relation to alexithymia, mindfulness, and self-criticism. Psychol Psychother 85: 374-390.

42. Gilbert P (2010a) Compassion focused therapy: Distinctive features. Routledge, London.

43. Gilbert P (2010b) Compassion focused therapy [Special issue]. Int J Cogn Psychother 3: 95-201.

44. Da Silva DR, Rijo D, Salekin RT (2015) The evolutionary roots of psychopathy. Aggress Violent Beh 21: 85-96.

45. Pasalich D, Dadds M, Hawes D, Brennan J (2012) Attachment and callous unemotional traits in children with early-onset conduct problems. J Child Psychol Psychiatry 53: 838-845.

46. Dadds MR, Allen JL, McGregor K, Woolgar M, Viding E, et al. (2014) Callous-unemotional traits in children and mechanisms of impaired eye contact during expressions of love: a treatment target? J Child Psychol Psychiatry 55: 771-780.

47. Marsh AA, Blair RJR (2008) Deficits in facial affect recognition among antisocial populations: A meta-analysis. Neurosci Biobehav Rev 32: 454-465.

48. Dadds MR, Gale N, Godbee M, Moul C, Pasalich DS, et al. (2015) Expression and Regulation of Attachment-Related Emotions in Children with Conduct Problems and Callous-Unemotional Traits. Child Psychiatry Hum Dev 47: 647-656.

49. Kindt M, Soeter M (2013) Reconsolidation in a human fear conditioning study: a test of extinction as updating mechanism. Biol Psychol 92: 43-50.

50. Loewenstein G, Weber E, Hsee C, Welch N (2001) Risk as feelings. Psychol Bull 127: 267-286.

51. Gross JJ, Levenson RW (1993) Emotional suppression: physiology, selfreport, and expressive behaviour. J Pers Soc Psychol 64: 970-986.

52. Willoughby M, Mills-Koonce W, Gottfredson N, Wagner N (2013) Measuring Callous Unemotional Behaviours in Early Childhood: Factor Structure and the Prediction of Stable Aggression in Middle Childhood. J Psychopathol Behav Assess 36: 30-42.

53. Bernstein A (2001) The Fear of compassion. Mod Psychoanalysis 26: 209-219.

54. Frick PJ (2004) The Inventory of Callous-Unemotional Traits. Unpublished rating scale.

55. Vinay JP, Darbelnet J (1995) Comparative stylistics of French and English: a methodology for translation (Vol. 11). John Benjamins Publishing.

56. Dancey C, Reidy J (2004) Statistics without Maths for Psychology: Using SPSS for Windows 1-33.

57. Huynh VW, Fuligni AJ (2010) Discrimination Hurts: The Academic, Psychological, and Physical Well-Being of Adolescents. J Res Adolesc 20: 916-941.

58. Ray J, Frick P, Thornton L, Steinberg L, Cauffman E (2016) Positive and negative item wording and its influence on the assessment of callousunemotional traits. Psychol Assess 28: 394-404. 
Citation: Maziatul Akmal K, Foong ALS (2018) Attachment Styles: Fear of Compassion and Callous-Unemotional Traits among Juvenile

Page 8 of 8

59. Chentsova-Dutton YE, Chu JP, Tsai JL, Rottenberg J, Gross JJ, et al. (2007) Depression and emotional reactivity: variation among Asian Americans of East Asian descent and European Americans. J Abnorm Psychol 116: 776.

60. Yang LH, Kleinman A, Link BG, Phelan JC, Lee S, et al. (2007) Culture and stigma: adding moral experience to stigma theory. Soc Sci Med 64 1524-1535.

61. Zimmermann P, Iwanski A (2015) Attachment in middle childhood: Associations with information processing. New Dir Child Adolesc Dev 148: 47-61.

62. Groh AM, Roisman GI, van IJzendoorn MH, Bakermans-Kranenburg MJ, Fearon RP (2012) The significance of insecure and disorganized attachment for children's internalizing symptoms: A meta-analytic study. Child Dev 83: 591-610.

63. Santascoy N, Burke S, Dovidio J (2016) Avoidant attachment style predicts less positive evaluations of warm (but not cold) social groups. Group Process Intergroup Rel 21: 19-36.

64. McKenna YE (2009) Cultural influences on attachment behaviours (Doctoral dissertation, Lethbridge, Alta.: University of Lethbridge, Faculty of Education, c2009).

65. Smiley AS (2016) A Systematic Review of Attachment-Based Interventions for Caregivers and Young Children Living in Poverty (Doctoral dissertation, University of Kansas).

66. Mula M, Danquah-Boateng D, Cock HR, Khan U, Lozsadi DA, et al. (2016) Different attachment styles correlate with mood disorders in adults with epilepsy or migraine. Epilepsy Behav 54: 110-114.

67. Soeter M, Kindt M (2010) Dissociating response systems: erasing fear from memory. Neurobiol Learn Mem 94: 30-41.

68. Allen JL, Morris A, Chhoa CY (2016) Callous-unemotional (CU) traits in adolescent boys and response to teacher reward and discipline strategies. Emotional Behav Difficulties 1-14.

69. Joeng JR, Turner SL (2015) Mediators between self-criticism and depression: Fear of compassion, self-compassion, and importance to others. J Couns Psychol 62: 453-463.

70. Allen JP, Hauser ST, Borman-Spurrell E (1996) Attachment theory as a framework for understanding sequelae of severe adolescent psychopathology: an 11-year follow-up study. J Consult Clin Psychol 64: 254-263.

71. Lindquist KA, Wager TD, Bliss-Moreau E, Kober H, Barrett LF (2012) What are emotions and how are they created in the brain?. Behav Brain Sci 35: 172-202.

72. Wells C, Wollack J (2003) An Instructors Guide to Understanding Test Reliability. Testing \& Evaluation Services. University of Wisconsin, Madison.
73. Gilbert P, McEwan K, Catarino F, Baião R, Palmeira L (2014) Fears of happiness and compassion in relationship with depression, alexithymia, and attachment security in a depressed sample. Br J Clin Psychol 53: 228-244.

74. Frick PJ, Cornell AH, Bodin SD, Dane HE, Barry CT, et al. (2003) Callous-unemotional traits and developmental pathways to severe conduct problems. Dev Psychol 39: 246-260.

75. Frick PJ, Ray JV, Thornton LC, Kahn RE (2014) Can Callousunemotional traits enhance the understanding, diagnosis, and treatment of serious conduct problems in children and adolescents? A comprehensive review. Psychol Bull 140: 1-57.

76. Roose A, Bijttebier P, Decoene S, Claes L, Frick PJ (2010) Assessing the affective features of psychopathy in adolescence: a further validation of the inventory of callous and unemotional traits. Assessment 17: 44-57.

77. Kimonis E, Frick P, Skeem J, Marsee M, Cruise K, et al. (2008) Assessing callous-unemotional traits in adolescent offenders: Validation of the Inventory of Callous-Unemotional Traits. Int J Law Psychiatry 31: 241-252.

78. Hofstede G, McCrae RR (2004) Personality and culture revisited: Linking traits and dimensions of culture. Cross-Cult Res 38: 52-88.

79. Human Rights Commission of Malaysia (SUHAKAM) (2009) Human rights and the administration of juvenile justice: SUHAKAM's conference in conjunction with Malaysian human rights day 2008. Malaysia: Ideamas Editorial Services.

80. Keshavarz S, Baharudin R (2009) Parenting style in a collectivist cultures of Malaysia. Eur J Soc Sci 10: 66-73.

81. Kline RB (1998) Principles and practice of structural equation modeling. Guilford, New York.

82. Tabachnick BG, Fidell LS (2001) Using multivariate statistics. International student edition (4thedn). Allyn \& Bacon, Boston, MA.

83. Thompson RA (2000) The legacy of early attachments. Child Dev 71: $145-152$.

84. de Ruiter C, Chakhssi F, Bernstein DP (2015) Treating the Untreatable Psychopath. The Clinical and Forensic Assessment of Psychopathy: A Practitioner's Guide 388.

85. UNICEF (2013) The Malaysian Juvenile Justice System: A Study of Mechanisms for Handling Children in Conflict with the Law. Ministry of Women, Family and Community Development and UNICEF Malaysia.

86. Viding E, Simmonds E, Petrides KV, Frederickson N (2009) The contribution of callous-unemotional traits and conduct problems to bullying in early adolescence. J Child Psychol Psychiatry 50: 471-481.

87. Wootton J, Frick P, Shelton K, Silverthorn P (1997) Ineffective parenting and childhood conduct problems: The moderating role of callousunemotional traits. J Consult Clin Psychol 65: 301-308. 